\title{
Alcohol breath testing in patients with respiratory disease
}

The Road Safety Act 1967 introduced in Great Britain the concept of a statutory limit to the amount of alcohol legally permitted in a driver's body. Under this Act the maximum legal limit was set at $80 \mathrm{mg} / 100 \mathrm{ml}$ in blood and $107 \mathrm{mg} /$ $100 \mathrm{ml}$ in urine. The motorist was required to take a screening roadside breath test and if the result was positive the subject was arrested and taken to a police station for a blood or urine test. In 1974 the Blennerhasset Committee recommended that breath analysis should replace blood analysis, and evidential breath testing came into force in May 1983. At present the law concerning drink and motor vehicles is defined in the Road Traffic Act 1988, sections $4-11 .^{1}$

\section{Alcohol breath tests and the law}

Under section 6 a constable in uniform may require a person he suspects of driving or being in charge of a motor vehicle while he has alcohol in his body, or who has committed a moving traffic offence or been in an accident, to provide a specimen of breath for a breath test (this is a preliminary roadside test to obtain an indication of whether the alcohol concentration is above the prescribed limit). A person who without a reasonable excuse fails to provide a specimen of breath at the roadside is guilty of an offence. A constable may arrest without warrant if the roadside test indicates that the breath alcohol concentration is above the prescribed limit or if a specimen of breath is not provided. The approved devices for roadside breath tests are the following: Alcotest 80, Alcotest 80A, Alcolyser, Alcolmeter S L2, Alert, and Alcolmeter S L2A.

Under sections 7-10, after arrest and transfer to the police station, the subject may be required to provide two specimens of breath or a specimen of blood or urine for analysis. The latter specimens cannot be requested unless the constable has reasonable cause to believe that for medical reasons a specimen of breath cannot be provided, or no reliable approved device is available for analysing the breath sample. The approved devices are the Lion Intoximeter 3000 and the Camic Breath Analyser. A person who without reasonable cause fails to provide a breath specimen when required to do so under this section is guilty of an offence. A constable must warn the person that failure to provide a specimen may make him or her liable to prosecution. Two specimens of breath must be provided; the one with the lower alcohol concentration is used and the other disregarded. The prescribed limit for breath alcohol has been set at $35 \mu \mathrm{g} / 100 \mathrm{ml}$ of breath. A person is not considered to have provided a specimen for a breath test unless the specimen $(a)$ is sufficient to enable the test or the analysis to be carried out, and $(b)$ is provided in such a way as to enable the objective of the test or analysis to be satisfactorily achieved (section 11).

A patient in hospital cannot be required to give a specimen for breath or laboratory analysis without the permission of the medical practitioner in immediate charge of his case.

The following safeguards are built into these procedures to protect the individual from unjust prosecution for having an alcohol concentration above the prescribed limit: 1 The original choice of $80 \mathrm{mg} / 100 \mathrm{ml}$ in Britain as the upper limit for blood alcohol rather than a lower concentration makes allowance for the varying susceptibility of different individuals to the effect of alcohol on driving competence (many experts, however, now believe $80 \mathrm{mg}$ / $100 \mathrm{ml}$ to be too high a limit).

2 Six mg (3 SE of difference of repeat measurements) is deducted from the measured blood alcohol concentration to allow for chance variation in the precision of the analysis. 3 The lower value obtained from the two breath samples is used.

4 The subject is not prosecuted if the breath alcohol is 35$39 \mu \mathrm{g} / 100 \mathrm{ml}$ breath. This is to allow for variation in the precision of the breath analysis.

5 There is a statutory right to have a blood sample taken if the breath alcohol level is $40-49 \mu \mathrm{g} / 100 \mathrm{ml}$. If this option is taken the breath alcohol result is disregarded-a safeguard designed to allow for physiological variation in the bloodbreath conversion factor resulting from differences in body temperature, breath temperature, and packed cell volume, and for whether the subject is in the postabsorptive phase or not. ${ }^{2}$

There is, however, no similar protection against unfair prosecution for the offence of failure to provide a breath sample. The constable has to decide whether there are medical reasons why a specimen of breath could not be provided and only on this basis can he offer a blood or urine test to someone who has failed to give a satisfactory breath sample. The courts are seen as the place in which any inappropriate charge can be reversed. The High Court ${ }^{3}$ ruled that the fact that a person had tried as hard as he could to give a breath sample did not amount to a reasonable excuse. Some additional evidence was necessary to show that he was unable to provide a suitable sample.

Because of public concern in 1984 about the performance of the evidential breath testing instruments (the Lion Intoximeter 3000 and the Camic Breath Analyser), a decision was taken to monitor the performance of these instruments for six months. ${ }^{4}$ The statutory option of a blood test if the breath alcohol concentration was $50 \mu \mathrm{g} /$ $100 \mathrm{ml}$ or below was extended on a non-statutory basis to all motorists who gave a breath sample irrespective of alcohol concentration; this non-statutory option was then continued until February 1989. During this period motorists who failed to provide a breath specimen without reasonable excuse were the only ones not permitted to give blood or urine. One of the conclusions of the six month survey was that as only $2.9 \%$ of subjects were unable to fulfil the requirement of the breath test this aspect did not appear to be a widespread problem. This percentage does not include those wilfully refusing to blow, but does include those with a medical excuse and those described as too drunk to blow. Figure 1 shows more recent data from the Home Office summary of the outcome of breath testing in England and Wales in $1988,{ }^{5}$ when $5.9 \%$ of those asked to give an evidential breath sample (6900 of 116200$)$ failed 


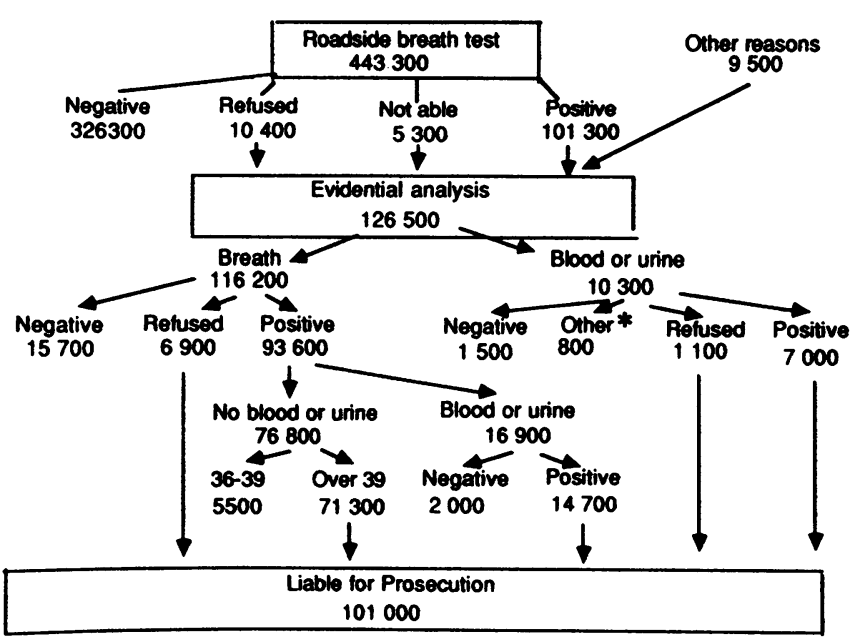

Figure 1 Outcome of the 443300 roadside breath tests undertaken in England and Wales in 1988. "Other reasons"-persons arrested on the grounds that their ability to drive was impaired by consumption of alcohol or drugs, or required to take an alcohol test after being arrested for other reasons.

"Other"-doctor objected or other outcome.

to do so. This figure does not include those thought to have a medical excuse as they would have been asked to give blood.

The penalty for the offence of "failure to provide" is a mandatory disqualification from driving for a minimum of 12 months plus a fine (maximum $£ 2000$ ) or a term of imprisonment (maximum six months) or both. In Oxford the penalty for failure is usually more severe than that for being over the prescribed alcohol limit (Oxford Magistrates Court, personal communication), presumably on the grounds that a person will fail to provide a breath sample only if he knows he is well above the prescribed limit.

\section{Alcohol breath tests in patients with respiratory disease}

There are two concerns about alcohol breath tests in patients with respiratory disease. Firstly, can breath alcohol be reliably converted to blood alcohol concentration in such patients and, secondly, can such patients give breath samples acceptable to the various analysers?

RELATION OF BREATH TO BLOOD ALCOHOL CONCENTRATION Although the partition coefficient for ethanol in vitro at $34^{\circ} \mathrm{C}$ is 2100 the Home Office has chosen $2300^{67}$ as the blood-breath factor-that is, 2.3 litres of originally saturated alveolar air when delivered at the mouth contains the same amount of alcohol as $1.0 \mathrm{ml}$ of postabsorptive venous whole blood with a normal packed cell volume and at normal body temperature. The findings in the six month survey support this choice. In the Lion Intoximeter group of 815 subjects in whom the apparent blood:breath ratio (range 1900-3100) was calculated from simultaneous blood and breath samples, $37 \%$ were in the range $2200-2400$, $52 \%$ over 2400 , and only $11 \%$ below 2200 . The safeguards mentioned previously mean that a subject with an actual conversion factor as low as 1800 will not unfairly face prosecution. Sir William Paton has drawn attention to what he called "unjustifiable non-prosecutions" in subjects with blood-breath factors above 2300 . $^{4}$

There are theoretical grounds for expecting more variability in the blood-breath factor within and between individuals in patients with airflow obstruction and uneven ventilation, as the use of a single factor assumes that the breath sample is well mixed, representative alveolar air in contact with capillary blood. Haas and Morris ${ }^{8}$ looked at 24

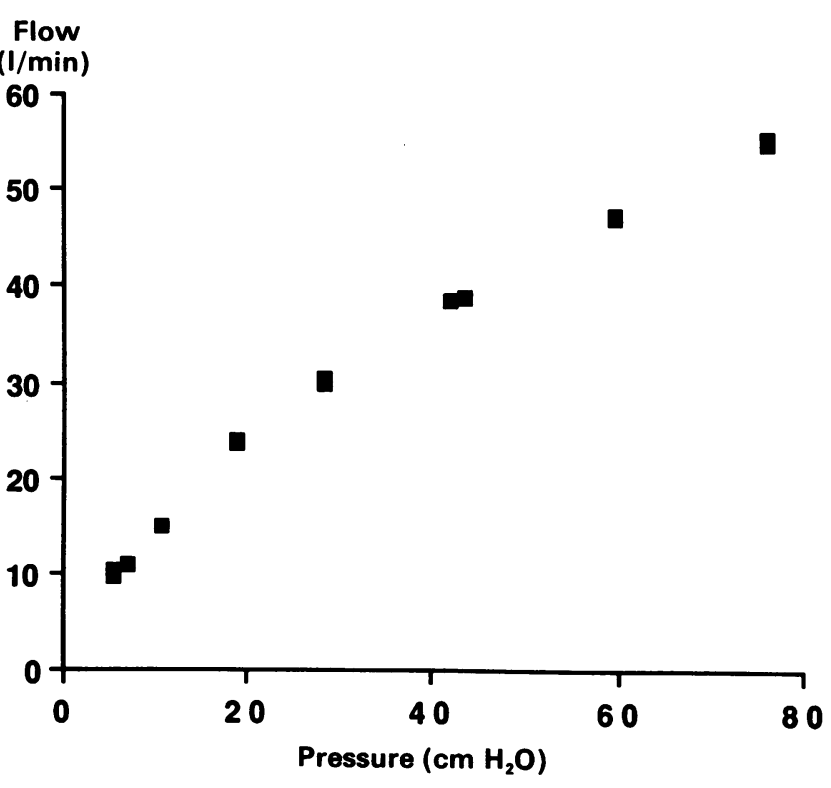

Figure 2 Graph of flow versus pressure when known constant flows were passed through an Intoximeter. Pressure was measured on a mercury manometer.

patients with chronic pulmonary disease, measuring breath alcohol with a Breathalyzer 900 and arterial blood alcohol by gas-liquid chromatography. They found no systematic difference in blood-breath relationships between patients with chronic pulmonary disease and previously studied populations not classified by pulmonary function. Russell and Jones found more variability in the breath concentration of alcohol as expiration proceeded from total lung capacity to residual volume in 10 patients with chronic obstructive disease than in 10 normal subjects. ${ }^{9}$ The Breathalyzer $900 \mathrm{~A}$, which they used, analyses the last part of the volume exhaled (as does the Lion Intoximeter) and in patients with chronic airflow obstruction this sample may well not represent mixed alveolar air. In the normal subjects breath ethanol concentration increased steadily as expiration proceeded to residual volume, but in some of the patients with airflow obstruction the concentration decreased as the volume expired increased. Higher bloodbreath partition coefficients were seen in 10 patients with chronic airflow obstruction using the Breathalyzer than in 10 normal subjects ${ }^{10}$; the use of a standard blood-breath factor led to underestimation of blood alcohol in their patients, again a conservative error in medicolegal terms. The only data on blood-breath factors in patients with pulmonary disease when breath alcohol measurements are obtained from devices approved in Britain are published as an abstract by Johnson et al. ${ }^{11}$ They found that the bloodbreath ratios in 10 patients selected from their chest clinic were within the normal range.

\section{CAN PATIENTS WITH RESPIRATORY DISEASE GIVE AN} ADEQUATE BREATH SAMPLE FOR ANALYSIS?

The Lion Alcolmeter S L2, one of the roadside screening devices commonly used in Britain, is activated by a flow rate of 28 litres a minute or more, which turns on a light and a timer. A second light is triggered if the flow rate is maintained for 2.7 seconds-giving a minimum expired volume of 1.25 litres. The reading is indicated as being above, roughly the same as, or below the legal limit of $35 \mu \mathrm{g} / 100 \mathrm{ml}$. As a screening device it performs well (fig 1). When Briggs et al ${ }^{12}$ asked 26 patients with an $\mathrm{FEV}_{1} / \mathrm{FVC}$ below $60 \%$ to use an Alcolmeter simulator only 10 were able to produce a flow rate of $28 \mathrm{litres} / \mathrm{min}$ for $2 \cdot 7$ seconds. Subjects with an FEV 1 below 1.5 litres or an $\mathrm{FEV}_{1}$ below $50 \%$ predicted were very unlikely to be able to activate the 

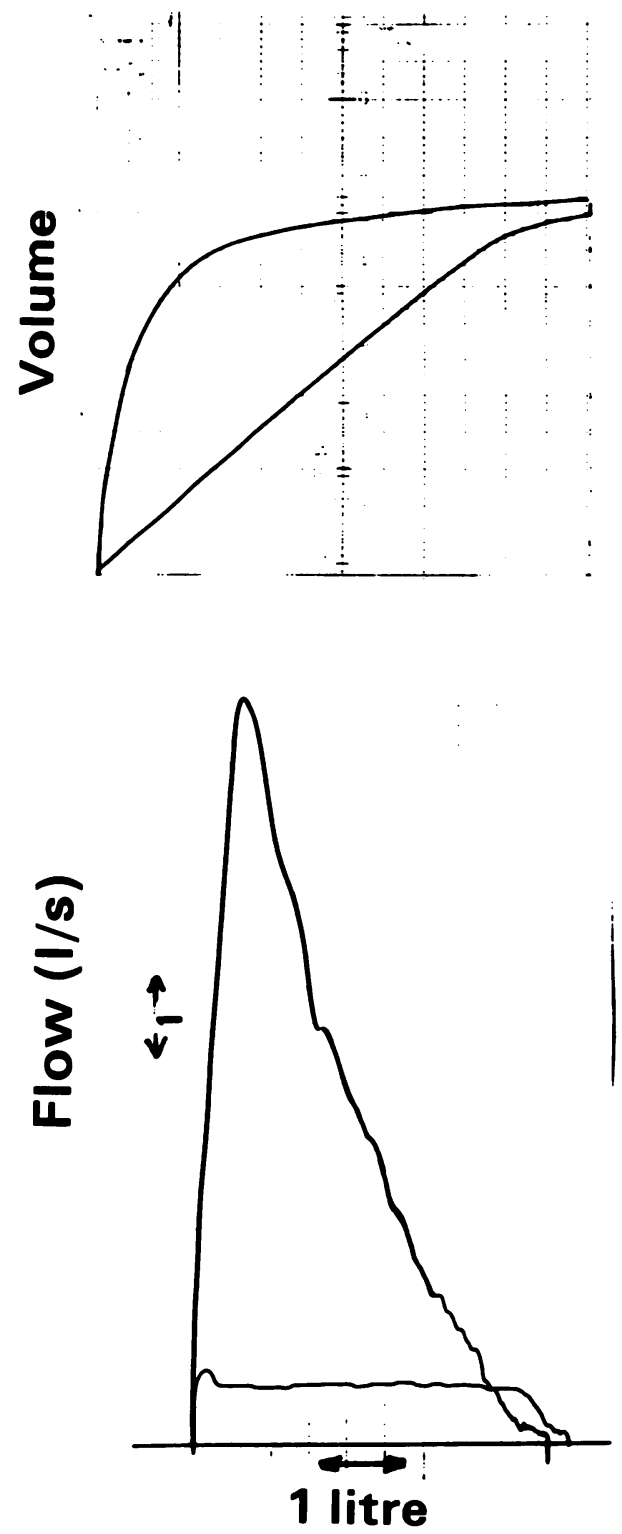
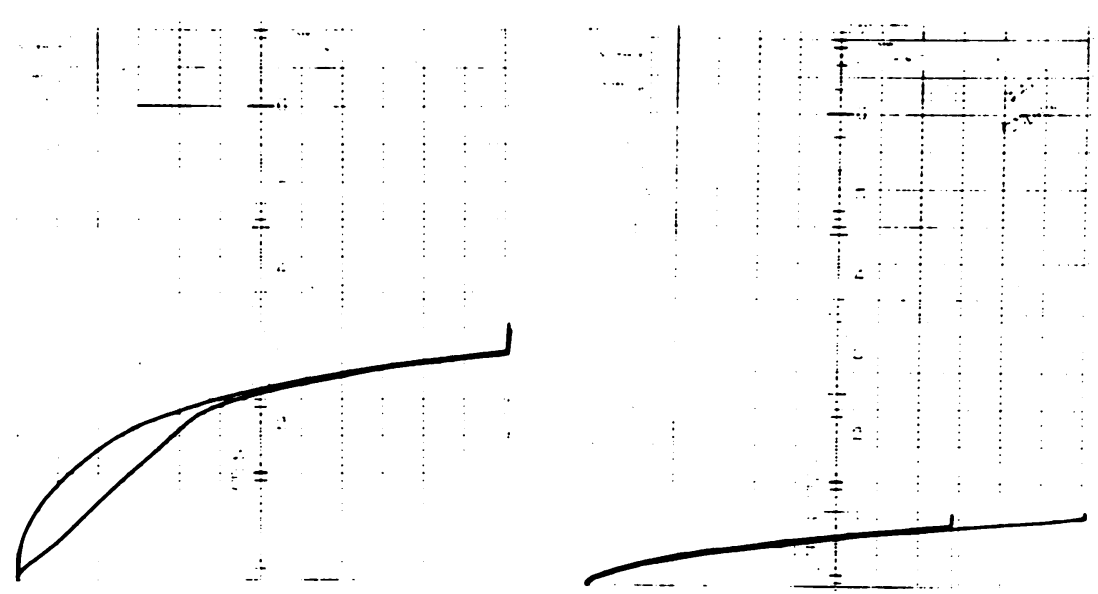

Time

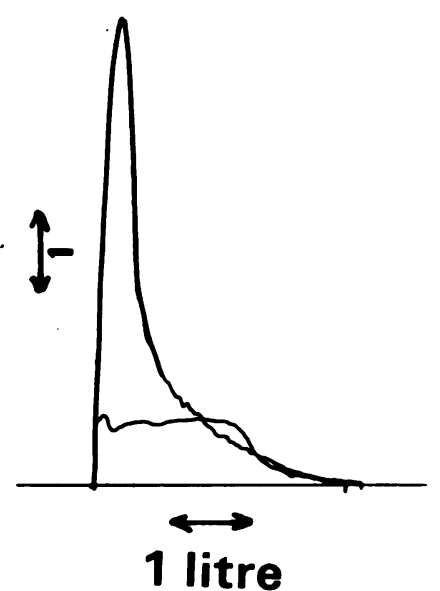

Volume

Figure 3 Graph showing volume-time and flow-volume tracings in three subjects. The tracings on the left (both upper and lower rows) are from a normal subject; the middle tracings are from a subject with moderate asthma and the ones on the right from a patient with severe chronic obstructive lung disease. On each graph forced vital capacity blows through both the Vitalograph mouthpiece and the resistance model of the Intoximeter are shown.

Alcolmeter. As 10 healthy subjects showed no significant difference in measured breath alcohol concentrations at expiratory flow rates of $10 \mathrm{l} / \mathrm{min}$ and $40 \mathrm{l} / \mathrm{min}$, the authors suggest that the screening device could be modified to allow for less stringent criteria for the way the breath is delivered.

When 51 patients selected at random from chest clinics were assessed their ability to use the breath testing instruments related to the results of spirometry (Johnson $e t$ al, abstract ${ }^{13}$ ). Patients with an $\mathrm{FEV}_{1}$ below 2 litres and an FVC below 2.61 were almost always unable to use the breath testing instruments; peak flow rate and $\mathrm{FEV}_{1} / \mathrm{FVC}$ ratio were poor predictors. Patients with restrictive and obstructive defects were similarly affected.

Our own experience with patients has been more anecdotal. ${ }^{14}$ We have been asked to assess patients ( 21 in all) who had failed to provide a breath sample for the Lion Intoximeter, and who claimed that they did their best to provide the sample as requested. Their lung function tests showed various patterns, including normal, apparent respiratory dyspraxia, mild restriction, and mild to severe airways obstruction, and one patient was unable to make a good seal on the mouthpiece owing to previous facial nerve injury. These individuals had been selected for evidential breath testing for having been over the prescribed limit (or borderline) for breath alcohol on a roadside screening device, or for having failed to provide a satisfactory sample to such a device. The instructions for the Lion Intoximeter specify that at least 1.5 litres of breath must be delivered in a continuous expiration at a flow rate of 10 litres/min or more-that is, within nine seconds. A minimum pressure of $10 \cdot 2 \mathrm{~cm} \mathrm{H}_{2} \mathrm{O}$ is required. One and a half litres was chosen by the Home Office to ensure that alveolar air was analysed, but it seems generous in view of the known volume of the anatomical dead space and the tubing dead space of less than $200 \mathrm{ml}$ leading to the infrared analyser, which takes a $70 \mathrm{ml}$ sample. For most of the patients we assessed, however, 1.5 litres seemed a modest and attainable volume and we were surprised that they had difficulty with this. We examined several Lion Intoximeters in line with a hand held spirometer and found almost complete overlap between the volumes that were accepted (range 1.3-4.0 litres) and those rejected $(1 \cdot 2-3 \cdot 5$ litres $)$. The harder the blow the larger the volume required for the Intoximeter to print a 


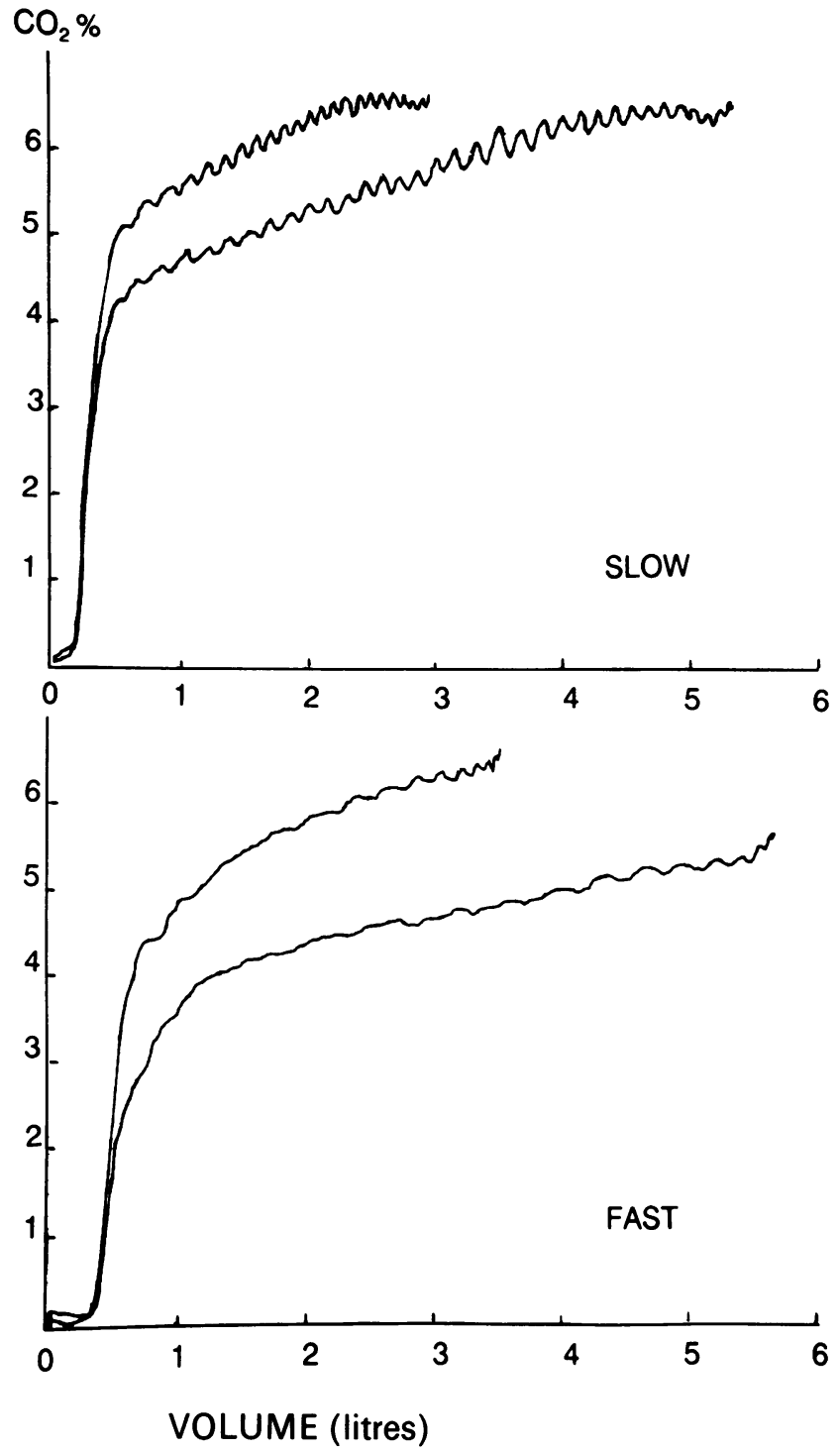

Figure 4 Graph showing expired carbon dioxide level in a normal subject breathing out to residual volume through a resistance model of the Lion Intoximeter slowly (upper panel) and fast (lower panel), after a tidal breath in and from total lung capacity. Expiratory times were 10 and 15 seconds (slow expirations) and 5 and 7 seconds (fast expirations).

result of the analysis. This finding was confirmed with a series of constant flows run through the Intoximeter up to the level of flow that could be generated by a young, healthy man. The test aborted when $2 \cdot 8$ litres was delivered in four seconds and when $3 \cdot 2$ litres was delivered in three seconds, but the machine accepted 1.7 litres delivered over 13 seconds. We have not had access to the flow measuring device in the Lion Intoximeter so are unable to explain this apparent overestimation of volume when the breath is delivered at high pressure.

The Lion Intoximeter with its $7 \mathrm{~mm}$ mouthpiece and $9 \mathrm{~mm}$ tubing internal diameter offers a considerable, but close to linear, resistance to flow (fig 2). The effect of this high resistance on subjects with and without airways obstruction is shown in figure 3 . In normal subjects the $\mathrm{FEV}_{1}$ is substantially reduced when the manoeuvre is done through a resistance model of the Lion Intoximeter; but there is less change, both real and proportional, in subjects with airflow obstruction. The expiratory flow-volume curves explain this apparent paradox showing that, despite the added external resistance, as airflow obstruction becomes more severe more of the flow-volume curve follows the effort independent part of the curve. Thus as intrinsic airflow resistance increases flow is eventually limited by the intrathoracic resistance, and the added external resistance has little additional effect.

The Lion Intoximeter is computerised so that the operator has no control of events or of the printout after the test has been initiated (again an effort to safeguard the rights of the subject). There is usually only time for two or three attempts to give the first of the two mandatory samples of breath. If this sample is not given in the required time no further attempts are allowed and an offence has been committed. Similarly, if the first sample is given satisfactorily but a second sample is not, an offence has been committed.

We have looked at expired carbon dioxide (measured by mass spectrometry) as a model for expired alcohol. Figure 4 shows that as a normal subject breathes out to residual volume there is a steady rise in the plateau reading of carbon dioxide towards mixed venous levels. Carbon dioxide is not a perfect model for alcohol: the much greater solubility of alcohol allows more interaction between ethanol vapour and the mucus membrane and mucus "blanket" in the airways. ${ }^{15}$ Many studies have shown a steady increase, similar to that of carbon dioxide, in plateau breath alcohol ${ }^{71718}$ This increase parallels the increase in breath temperature at the mouth as expiration proceeds. ${ }^{15-17}$ Correction of the blood-breath factor for temperature difference from $34^{\circ} \mathrm{C}$ at the mouth does not completely correct the blood-breath discrepancy. Carbon dioxide and alcohol have some features in common, such as the diluting effect of a large inspiration, the effect of breath holding, and the sequence of alveolar emptying, poorly ventilated alveoli emptying close to residual volume. Because of the steady increase in breath alcohol concentration with expiration, discarding volumes as great as 2.6 litres has been recommended. ${ }^{17}$ The Home Office has chosen to use a combination of a discard volume of 1.5 litres and an apparent blood-breath factor of 2300.

Thus there are difficulties in requiring breath samples from patients with respiratory disease and from people with small lungs. There may also, I believe, be problems with the Lion Intoximeter for people with a vital capacity above 3 litres who do not carry out breathing manoeuvres well in response to commands, because of nervousness, age, or some degree of respiratory dyspraxia. Measuring the alcohol concentration in the body by doing a blood or urine test in those who fail to give a satisfactory breath sample would seem preferable to charging them with the offence of "failure to provide." The concern is that if this were allowed there might be widespread intentional failure to give a breath sample as a delaying tactic.

The OIML (Organisation internationale de metrologie legale) is at present preparing international specifications for breath testing devices. As a result it is possible that future instruments will measure the alcohol concentration plateau without the constraints of a volume and pressure requirement.

\section{JOCELYN MORRIS Osler Chest Unit,} Churchill Hospital,

Address for reprint requests: Osler Chest Unit, Churchill Hospital, Oxford OX3 7LJ.

I would like to thank Alison-Grace Taylor, Fiona McConnachie, and the Thames Valley Police for their help in the measurements made in the local Police Stations. R G Madgwick, Allen and Hanburys respiratory technician, and the Home Office scientists P J Gomm and C G Broster made the measurements on the Home Office Lion Intoximeters, and I am most grateful to them. 
1 Road Traffic Act 1988. Sections 4-11, 2/128-33.

2 Jones AW. Variability of the blood:breath ratio in vivo. $J$ Studies Alcohol 1978;39:1931-9.

3 Grady $v$ Pollard. The Times Law Report. 16 February 1988.

4 Cobb PGW, Dabbs MDG (Foreword by W Paton). Report on the performance of the Lion Intoximeter 3000 and the Camic Breath Analyser evidential breath alcohol measuring instruments during the period 16 April 1984 to 15 October 1984. London: HMSO, 1985.

5 Home Office Statistics of breath tests, England and Wales 1988. Home Office Statistical Bulletin 1989;28:1-11.

6 Wright BM, Jones TP, Jones AW. Breath alcohol analysis and the blood:breath ratio. Med Sci Law 1975;15:205-10.

7 Begg TB, Hill ID, Nickolls LC. Breathalyzer and Kitagawa-Wright methods of measuring breath alcohol. Br Med J 1964;i:9-15.

8 Haas HH, Morris JF. Breath alcohol analysis in chronic bronchopulmonary disease. Arch Environ Health 1972;25:114-8.

9 Russell JC, Jones RL. Breath ethyl alcohol concentration and analysis in the presence of chronic obstructive pulmonary disease. Clin Biochem 1983;16:182-7.

10 Wilson A, Sitar DS, Molloy WD, McCarthy D. Effect of age and chronic obstructive pulmonary disease on the breathalyzer estimation of blood alcohol level. Alcoholism. Clin Exp Res 1987;11:440-3.

11 Johnson NMcI, Upton K, Gomm PJ, Broster CG, Osselton MD. Use of bronchodilators in conjunction with evidential breath alcohol testing devices by patients with respiratory diseases. Thorax 1990;45:342P.

12 Briggs JE, Patel H, Butterfield K, Honeybourne D. The effects of chronic obstructive airways disease on the ability to drive and to use a roadside alcolmeter. Respir Med 1990;84:43-6.

13 Johnson NMcI, Upton K, Gomm PJ, Broster CG, Osselton MD. Ability of patients with respiratory diseases to use breath alcohol measuring devices. Thorax 1989;44:846P.

14 Morris MJ, Taylor AG. Failure to provide a sample for breath alcoho analysis. Lancet $1987 ; \mathrm{i}: 37$.

15 Jones AW. How breathing technique can influence the results of breath alcohol analysis. Med Sci Law 1982;22:275-80.

16 Jones AW. Quantitative measurements of the alcohol concentration and the temperature of breath during a prolonged exhalation. Acta Physiol Scand 1982;114:407-12.

17 Dubowski KM. Biological aspects of breath alcohol analysis. Clin Chem 1974;20:294-9. 